EPiC Series in Built Environment
Volume 1, 2020, Pages 133-141
Associated Schools of Construction Proceed-
ings of the 56th Annual International Conference

\title{
Trends Associated with ASC Annual Conference Proceedings from 2004-2019
}

\author{
Clifton B. Farnsworth, Ph.D., P.E. and Evan D. Bingham, Ph.D. and James P. Smith. Ph.D. \\ Brigham Young University \\ Provo, Utah
}

The Proceedings of the Associated Schools of Construction (ASC) Annual International Conference include scholarly work associated with construction education and research. This conference is a resource for ASC member institutions to publish their scholarly endeavors. However, the relative impact of the annual proceedings is not well understood. The purpose of this paper is to explore the trends associated with the annual conference proceedings from 2004-2019, including a comparison of papers published by author and institution, international and collaborative efforts, and the type of research that is being published. This paper demonstrates that the demand to publish at the ASC annual conference continues to increase. Alternative and innovative solutions to accommodate this continued growth should be considered. Over the past 16 years, the annual conference proceedings have been a publishing resource for 1,212 unique authors, representing 276 different institutions. International and collaborative efforts have been reasonably strong and appear to be one of the strengths of the conference. Although the international presence seems to help validate the importance of the conference in construction related research, there also appears to be room to continue to grow this aspect of the conference.

Key Words: ASC Conference Proceedings, Academic Impact, Construction Research

\section{Introduction}

The Associated Schools of Construction (ASC) is an organization of approximately 150 construction related programs from higher education institutions, that "promotes the sharing of ideas and knowledge, and inspires, guides and promotes excellence in curricula, teaching, research and service" (ASC, 2019a). One of the key ways that the ASC supports the advancement and sharing of knowledge is through their annual conference and publication of the annual international conference proceedings. The ASC vision and mission statement both include scholarship related statements, including "inspiring excellence in research" and "advancing construction education by supporting members in research innovation," respectively (ASC, 2019b). Nearly thirty years ago, a paper presented at the ASC annual conference indicated that "organized research in the construction discipline is in its infancy," and that "as young construction programs mature, they gain an interest in developing a research component" (Rounds, 1991). Another paper stated that "construction research and 
technology transfer activities appear to be on the verge of explosive growth" (Badger, 1990). It appears that at the time, construction related research was not a mainstream part of most higher education construction programs. However, today many (if not most) ASC institutions have scholarship expectations that require the faculty to be involved with performing and publishing research. Obviously, the level of research activity varies from institution to institution. There are a number of reasons why supporting construction related research continues to be an important part of the Associated Schools of Construction. Research is the gateway for generation and dissemination of new knowledge, thus effectively solving problems and advancing the way that things are done. Students involved in research learn to think deeply, enhance their creativity, learn to solve problems, and strengthen their communication skills as they engage in rigorous research experiences. Promoting sound research methodologies and following effective peer review processes provides accuracy and reliability in results. Presentation of the work advances the dissemination of the knowledge, but in a more collaborative environment where a community of researchers begins to really develop. Ultimately, publishing research findings contributes to the body of knowledge, thus ensuring that the information is documented and made available to others without having to continuously "reinvent the wheel." It is presumed that for these reasons that the ASC continues to support research as a part of the annual conference and annual conference proceedings.

One of the comments that is frequently repeated during the annual ASC conference publications committee meeting is that many research-intensive institutions do not "count" publishing at an academic conference. Rather, these institutions expect faculty to make scholarly contributions by publishing their scholarly efforts through high-impact peer-reviewed academic journals. Although requirements vary from institution to institution, it is presumed that there are some universities within the ranks of the ASC that may fit this description. However, there are certainly other ASC schools for which a conference paper is a perfectly acceptable form of scholarly output. Either way, it is assumed that those individuals publishing their research within the annual ASC conference proceedings are getting some sort of credit for their scholarly efforts. Unfortunately, the level of impact that the annual ASC conference proceedings is having is not well defined. The purpose of this paper is to explore the trends associated with the annual conference proceedings from 2004-2019 to determine the role publishing at the annual conference plays across the ASC membership. To begin to understand this, it is important to identify "who is publishing" and "where are they from?" The principal elements addressed in this paper include an analysis of conference proceedings papers published by author and institution, identifying international and collaborative efforts, and what is generally being published. In presenting this data, the authors are in no way attempting to imply author or program superiority by more frequent publication. Rather, the intention is to simply allow institutions to more accurately define their peer group and establish a relative comparison, within the context of their individualized scholarly expectations. It should further be noted that this paper complements a similar paper (submitted to this same conference) on trends associated with the International Journal of Construction Education and Research (IJCER), the academic journal sponsored by the ASC. Because the IJCER has been in existence in its current form since 2004, the data for the ASC annual conference proceedings presented within this paper corresponds with this same timeframe.

\section{Background}

One widely accepted model for defining scholarship performed in higher education was introduced in 1990 by Boyer (however, referencing the more recent version; Boyer et al., 2015). The Boyer model of scholarship is defined as interlocking parts that include the scholarship of discovery, integration, application, and teaching (Boyer et al., 2015). Each of these elements is essential within the grand totality of construction scholarship encompassed by all higher education institutions; however, independently, each institution defines the appropriate context for scholarly expectations within their 
institution. For example, some institutions have a heavy emphasis on the scholarship of discovery, and faculty are expected to push the boundaries of knowledge within this discovery process. Yet, other institutions have a strong emphasis on the scholarship of teaching, that is disseminating knowledge within the classroom. Although sometimes seemingly lost in the shuffle of research expectations, it is also widely accepted that there ought to be a direct link between the teaching and research taking place within higher education (Brown and McCartney, 1998). The Boyer model embraces this implication. Other efforts have expanded upon the Boyer model to define that scholarship actually takes place within all of the traditional elements of academic responsibility, including teaching, research, and service (Hyman et al., 2002). Yet, despite these efforts, for many academics, the phrase "publish or perish" describes the heavier emphasis on publishing, whether it be discovery, integration, application, or teaching related scholarship. As such, individual higher education institutions have various ways of defining the impact of each of these types of efforts.

As indicated, one of the goals of the ASC vision and mission is to promote the advancement of construction knowledge and research. One specific way that this occurs is through the annual conference, which provides an opportunity for both presentation and publication of scholarly work. The aims of the International Proceedings of the Annual Conference include providing for the "dissemination of research that enhances and improves our teaching and learning processes within construction education and construction practice" (ASC, 2019c). The aims further state that "research can be defined as any effort of careful, systematic, patient study, and investigation in some field of knowledge, undertaken to discover or establish facts and principles" (ASC, 2019c). In general, it seems that the aims seem to support the idea of publishing scholarship across the entire spectrum of the Boyer model, from the scholarship of discovery to the scholarship of teaching. Historically, the conference has divided papers into two principal categories (education and practice), more recently with six subcategories incorporating undergraduate, graduate, research, and general related topics. The scope of the annual conference proceedings currently indicates that a broad spectrum of topics in the built environment is welcome, including (but not limited to) the following: "new and current technologies in construction, contracting, project delivery, legal issues, project management and controls, construction workforce and organizational management, construction materials, health, safety, and quality management" (ASC, 2019c). With such a breadth of potential topics, the ASC annual conference, in essence, has the potential to be a publication venue for practically any construction related scholarship occurring.

There is limited existing literature that relates to defining and understanding the relative impact of the ASC conference proceedings. Ghosh and Bhattacharjee (2013) performed a content analysis on 12 years of data (2000 through 2011). In their study, it was determined that the most frequent categories of topics published within the ASC proceedings include (in order) construction education, construction processes, management aspects, technological improvements, and asphalt and transportation. This paper demonstrated that there is indeed a wide range of potential topics published within the annual proceedings, supporting the mission of the ASC as noted above. Although not a part of the current study presented within this paper, it may be worth readdressing this concept with a little more precision in the topic area. Another recent paper has explored the expectations regarding publication of ASC member faculty (Sewalk et al., 2015), in which data from 81 responding ASC member institutions was used. The principal takeaways from their research include: first, most construction programs do not have specific list of approved publication venues, and even those that do generally allow flexibility based on the faculty research interests; second, the number of required publications and/or presentations necessary for advancement in rank and tenure varies, as expected. $59 \%$ required $0-5,20 \%$ required, $6-9$, and $21 \%$ required $10+$ publications and/or presentations. It should be noted that this research did not differentiate between journal vs. conference proceedings expectations and allowances. However, another question did indicate a preference for traditional 
academic metrics, preferring journals with impact factors, thus enhancing the likelihood for increased citation counts (Sewalk et al., 2015). The research contained in this paper is intended to complement and further these ideas. It should be noted that a third study also explored the number of papers published by various institutions in the ASC annual conference proceedings between 1986 and 2005 (Williamson and Burk, 2006). However, this study includes a more rigorous analysis of the trends associated with proceedings authorship and institution.

\section{ASC Conference Proceedings Statistics}

The ASC annual conference proceedings include a total of 1,140 published papers over the past 16 years (2004-2019), and comprises the complete dataset analyzed for this paper. Figure 1 shows the general increase in papers published in the proceedings over the past 16 years, from a low of 40 papers in 2004 to a high of 92 in 2019. It should be noted that the acceptance rate for papers generally stays about the same from year to year (about 65\%). It is, therefore, readily apparent that the demand for publishing at the annual conference is generally increasing. There are certainly many factors that could affect this. It might reflect increasing demands on faculty to produce scholarly work. However, it could also possibly reflect an increasing awareness and respect for the quality of the conference. Either way, it seems to support the idea that construction research is becoming an increasingly more important part of the mission of higher education construction programs. Papers submitted during this timeframe were divided into two principal categories: education and practice. Figure 1 also shows the number of papers published in each of these categories during this timeframe. From 2004 to 2011, the number of papers was nearly equal between these categories. However, beginning in 2012, the number of practice related papers have outweighed the number of education related papers. Again, this could be a reflection of the two possibilities identified above.

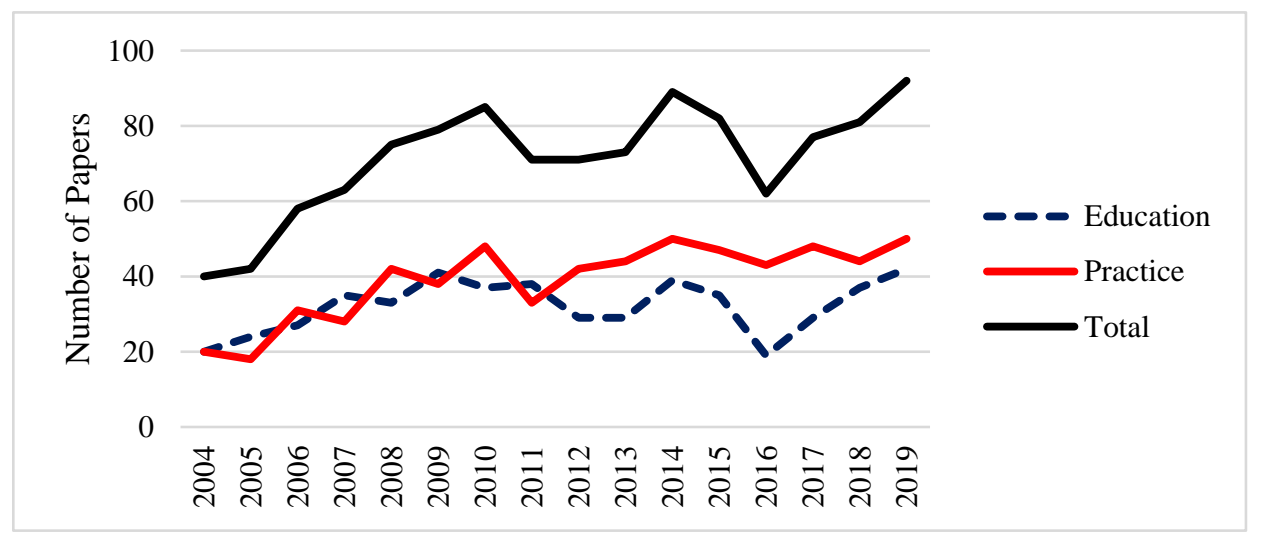

Figure 1. Category breakdown of conference proceedings papers

Table 1 identifies the total number of papers in each of the education and practice categories during this time period, as well as the further subdividing of six subcategories that papers could be submitted in. It should be noted that amongst the subdivided categories, the greatest increase has come through the research-practice subcategory, nearly doubling the amount of papers published in each of the other five subcategories each year. One subcategory that has clearly not been heavily supported is in graduate-education, averaging less than 2 graduate related publications per year. This appears to be an area that faculty ought to consider contributing to the body of knowledge. One of the big takeaways 
from the information contained in Figure 1 and Table 1 is the increasing demand for publishing in the annual proceedings. However, with constraints on the numbers of papers that can be presented at the annual conference within the current conference model, the authors recommend that the ASC look for innovative and alternative ways to promote and support this increasing demand.

Table 1

Number of papers published in various proceedings categories

\begin{tabular}{|c|c|c|c|c|c|c|}
\hline Category & Number & Percent & Subcategory & Number & Percent & No./Year \\
\hline \multirow{4}{*}{ Education } & \multirow{4}{*}{514} & \multirow{4}{*}{$45.1 \%$} & Undergraduate & 239 & $21.0 \%$ & 14.9 \\
\hline & & & Graduate & 24 & $2.1 \%$ & 1.5 \\
\hline & & & General & 134 & $11.8 \%$ & 8.4 \\
\hline & & & Research & 117 & $10.3 \%$ & 7.3 \\
\hline \multirow{2}{*}{ Practice } & \multirow{2}{*}{626} & \multirow{2}{*}{$54.9 \%$} & General & 222 & $19.5 \%$ & 13.9 \\
\hline & & & Research & 404 & $35.4 \%$ & 25.3 \\
\hline
\end{tabular}

One of the key elements of this research was exploring who publishes in the annual conference proceedings and identifying where they are from. A total of 1,212 unique authors have published in the annual conference proceedings since 2004. Of these different authors, 827 (68.2\%) have had their name associated with only a single manuscript. It is presumed that many of these are students or nonacademic collaborators. On the other hand, $385(31.8 \%)$ have published two or more papers. The highest three publishing authors have been associated with publishing 35, 26, and 22 papers, respectively. Figure 2 shows a breakdown of the number of papers that have been published by the corresponding number of authors. For example, $2.5 \%$ of the contributing authors have published 11 or more papers, $2.8 \%$ have published $8-10$ papers, etc. It should be noted that a number of authors have published at multiple institutions during this time period. The author information shown accounts for these changes. Although a list identifying the highest publishing authors is not shown, it generally correlates with the highest publishing institutions.

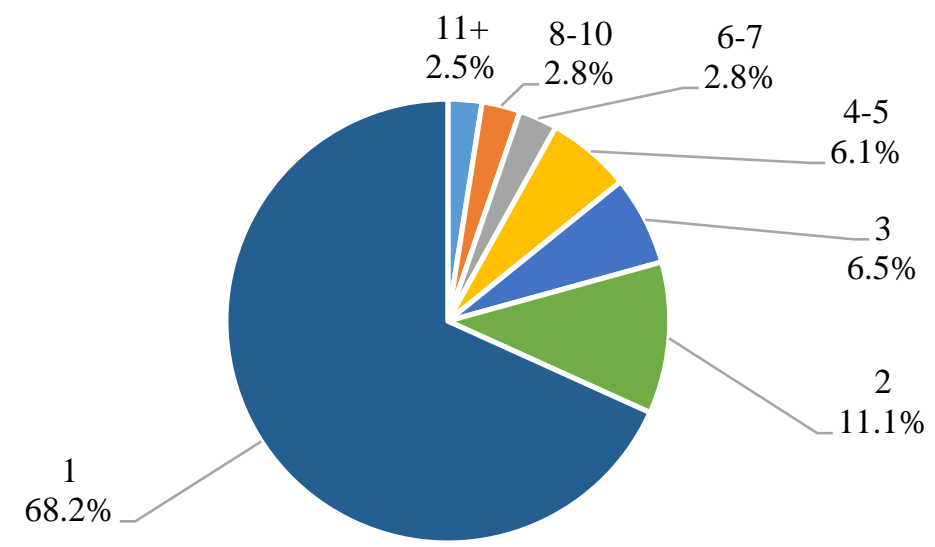

Figure 2. Number of papers published by contributing authors

Table 2 shows the highest number of papers associated with various institutions. Each unique institution affiliation for each paper was counted within this data. The data is based on the institutions 
for which each author was affiliated at the time of publication. A total of 276 different institutions were associated with the annual conference proceedings. As indicated earlier, it is presumed that faculty publishing in the annual conference proceedings merit some level of academic credit for these publications. It is interesting to note that many at the top of this list include universities with significant research expectations. However, there also universities included in this list that are predominantly undergraduate teaching focused institutions. It should not be presumed that any university not appearing at the top of the list is does not have scholarly expectations and is not performing research. Rather, this list simply represents those institutions that are the most significant contributors to the proceedings of the ASC annual conference. Future research should explore how these universities define the academic impact that the ASC conference proceedings provides them.

Table 2

Highest number of papers published by contributing institutions

\begin{tabular}{cc}
\hline Institution & Number of Papers \\
\hline Auburn & 139 \\
Colorado State University & 90 \\
Arizona State University & 67 \\
Texas A\&M University & 59 \\
Purdue University & 57 \\
University of Oklahoma & 39 \\
Clemson University & 35 \\
University of Florida & 34 \\
Virginia Polytechnic Institute and State University & 33 \\
California Polytechnic State University, San Luis Obispo & 31 \\
East Carolina University & 29 \\
Georgia Institute of Technology & 27 \\
University of Nebraska - Lincoln & 26 \\
Brigham Young University & 25 \\
Florida International University & 22 \\
Mississippi State University & 21 \\
Georgia Southern University & 20 \\
Dublin Institute of Technology & 16 \\
Southern Polytechnic State University & 16 \\
University of Salford & 16 \\
University of Southern Mississippi & 16 \\
Northern Arizona University & 15 \\
Northern Kentucky University & 15 \\
Roger Williams University & 15 \\
University of North Carolina at Charlotte & 15 \\
\hline
\end{tabular}

Table 3 shows a further breakdown of the institutions that were associated with publishing in the annual conference proceedings. As expected, the majority of the 276 contributing institutions are made up of academic institutions (about 2/3). The other $1 / 3$ of the contributing authors were associated with government, research, or private industry organizations. It is presumed that the majority of the individuals associated with non-academic institutions fit one of the following two categories: first, former students who were now working for these other organization types, or second, collaborators from these other organization types that were working with the university on the 
research. Since the majority of the ASC member institutions are U.S. based, it is interesting to compare the number of U.S. vs. non-U.S. based institutions. Table 3 indicates that the number of contributing U.S. academic institutions (134) is about 2.5 times that of contributing non-U.S. academic institutions (51). This is not too surprising, since at least one author must attend the conference to publish within the proceedings. However, it also represents an area for opportunity, in continuing to advance the reach of the Associated Schools of Construction outside of the U.S. The highest contributing international countries and the associated number of academic institutions from each country includes the United Kingdom (11), Australia (5), Hong Kong (5), Canada (4), Brazil (3), China (3), Egypt (3), and South Korea (3).

Table 3

Breakdown of contributing institutions

\begin{tabular}{ccc}
\hline Institution Type & U.S. & non-U.S. \\
\hline Academic & 134 & 51 \\
Government / Research & 14 & 1 \\
Industry & 64 & 12 \\
Total & 212 & 64 \\
\hline
\end{tabular}

To further explore the international component of the annual proceedings, a total of 23 different countries were represented within the compiled author affiliation information. This list includes the following countries: Australia, Brazil, Canada, China, Egypt, Finland, Hong Kong, India, Iran, Ireland, Jordan, Lebanon, New Zealand, Nigeria, Pakistan, Qatar, South Africa, South Korea, Sri Lanka, Turkey, United Arab Emirates, United Kingdom, and the United States. Although this list supports the international nature of the Associated Schools of Construction and the annual conference and proceedings, it further demonstrates that there is yet significant room to grow the international presence of the ASC.

One of the final elements explored within this research was the collaborative nature of the research being submitted for publication in the annual proceedings, including international collaboration. Table 4 shows that of the 1,140 manuscripts published, 296 of those papers included some form of collaborative effort between different institutions. This means that $26.0 \%$ of the papers submitted included author affiliation with two or more different institutions. It should be noted that collaboration within proceedings papers generally takes place more often with practice related papers than with education related papers. Again, these numbers certainly represent some former students that were now working elsewhere. However, a large portion of these papers also certainly represents authors from multiple institutions working together on the research. Collaboration between different institutions is inherently important because it has the potential to provide an additional layer of selfsupported peer review, thus generally leading to a higher quality of research performed. Table 4 also shows that 115 papers $(10.1 \%)$ included at least one author affiliated with an institution outside of the U.S., and 77 of the published papers $(6.8 \%)$ were authored strictly by authors at institutions outside of the U.S. This means that over the past 16 years, there have been on average 7 papers submitted a year with at least one non-U.S. based author. These numbers further validate the international nature of the ASC. Finally, 48 papers (4.2\%) included some element of international collaboration, that is at least two of the authors were affiliated with institutions residing in different countries. Although there is some international presence within the proceedings, it appears that increasing international participation at the annual ASC conference is an area that the ASC should continue to promote. This in turn could help strengthen the quality and impact of the ASC annual conference proceedings. 
Table 4

Collaborative and international involvement

\begin{tabular}{ccc}
\hline TITLE & Number of Papers & Percentage \\
\hline Authors from multiple organizations & 296 & $26.0 \%$ \\
At least one non-U.S. based author & 115 & $10.1 \%$ \\
All authors from non-U.S. based institutions & 77 & $6.8 \%$ \\
International collaboration & 48 & $4.2 \%$ \\
\hline
\end{tabular}

\section{Discussion}

The authors are commonly faced with two questions by their college administration when justifying the academic impact of their own scholarly works: "Who are your peers?" and "Where are they publishing?" Answering these questions has become especially critical for faculty going up for promotion and tenure. The authors were recently challenged to better define the venues where they typically publish, with encouragement to continue to publish in those that can be appropriately justified as a high-quality venue. Although preference is given for publishing in high-impact peer reviewed journals, the authors are encouraged to actively participate in publishing at scholarly conferences to become fully integrated within a community of scholars. The ASC annual conference has been one of the traditional venues for regularly publishing research for faculty from our program. Unfortunately, the scholarly impact of the ASC annual conference proceedings is not well understood. The purpose of this paper has been to explore the trends associated with the ASC proceedings, to help better define the scholarly community publishing through the ASC conference.

This research has addressed this in several ways. First, this research has indicated that there is an increasing demand to publish within the ASC proceedings. This ought to create a healthy competition, potentially raising the quality of both the research being performed and the papers submitted. Second, the large number of authors and institutions that has published within the ASC proceedings indicates a large community of scholars actively involved with the ASC annual conference. This ought to collectively correspond with an increasing body of expertise and potential peer review. The more individuals working on similar types of research, the better the research results should be all the way around. Third, the ASC proceedings is NOT just a conference for non-research institutions, but rather the opposite. The highest publishing institutions at the ASC annual conference are from well known $\mathrm{R} 1$ research institutions. This helps validate the level of research being published in the conference proceedings. Finally, the community of construction researchers extends beyond the boundaries of the ASC. The international and collaborative trends indicated by this research seem to demonstrate an increasingly impactful community of practice. However, continuing to grow the international presence within the ASC conference will certainly enhance the overall impact.

\section{Conclusions}

Supporting the production of the ASC annual conference proceedings is an essential service provided by the Associated Schools of Construction, with regard to providing publication opportunities for its member institutions. Although scholarly expectations vary amongst ASC member institutions, the demand for publishing at the annual conference continues to increase, and is heavily supported by both research and non-research institutions alike. Generating and sharing information related to 
furthering construction education and research supports the mission of the ASC. The purpose of this paper has been to explore the trends associated with the annual ASC conference proceedings papers published by author and institution, identifying international and collaborative efforts, and what is generally being published. In summary, the demand to publish at the ASC annual conference continues to increase. Alternative and innovative solutions to accommodate this continued growth should be considered. The annual proceedings has been a publishing resource for 1,212 unique authors, representing 276 different institutions. International and collaborative efforts have been reasonably strong and appear to be one of the strengths of the conference. Although the international presence seems to help validate the importance of the conference in construction related research, there appears to be room to continue to grow this aspect of the conference.

\section{References}

ASC (2019a). Associated Schools of Construction, General Information webpage: https://www.ascweb.org/about/general-information/ (accessed 10/29/2019).

ASC (2019b). Associated Schools of Construction, Vision and Mission Statements webpage: https://www.ascweb.org/about/mission-statement/ (accessed 10/29/2019).

ASC (2019c). Associated Schools of Construction, ASC Conference Proceedings webpage: http://ascpro.ascweb.org/ (accessed 10/29/2019).

Badger, W.W. (1990). ASC Future Direction Paper.” 26 $6^{\text {th }}$ ASC Annual International Conference Proceedings.

Boyer, E.L., Moser, D., Ream, T.C., \& Braxton, J.M. (2015). Scholarship reconsidered: Priorities of the professoriate. John Wiley \& Sons.

Brown, R.B. and McCartney, S. (1998). The Link between Research and Teaching: Its Purpose and Implications. Innovations in Education and Training International, 35:2, 117-129, DOI:

10.1080/1355800980350205

Ghosh, S. and Bhattacharjee, S. (2013). “A Systematic Review of Research Papers on Construction Education and Research: 2000-2011." 49 ${ }^{\text {th }}$ ASC Annual International Conference Proceedings.

Hyman, D., Gurgevich, E., Alter, T., Ayers, J., Cash, E., Fahnline, D., Gold, D., Herrmann, R., Jurs, P., Roth, D., Shwisher, J., Whittington, M.S., and Wright, H. (2002). Beyond Boyer: The UniSCOPE Model of Scholarship for the 21st Century. Journal of Higher Education Outreach and Engagement, 7(1\&2), 41-65.

Rounds, J. (1991). The State-of-the-Art of Construction Research. 27 ${ }^{\text {th }}$ ASC Annual International Conference Proceedings.

Sewalk, S., Taylor, M.J., Puddicombe, M., and Chinowsky, P. (2015). "A Survey of Construction Management Programs: Publications, Expectations and Compensation." $51^{\text {st }}$ ASC Annual International Conference Proceedings.

Williamson, K. and Burt, R.A. (2006). Continuing the Ranking Game: Using ASC Publication as One Criteria for the Ranking of C-Schools. $42^{\text {nd }}$ ASC Annual International Conference Proceedings. 